\title{
Chronic pectoralis major rupture in a 32-year-old man
}

\author{
Nata Parnes MD, Matthew M. Tomaino MD MBA
}

Cite as: CMAJ 2021 February 1;193:E172. doi: 10.1503/cmaj.201248

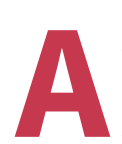

32-year-old, active man who worked in the military presented with left shoulder pain and weakness 6 months after sustaining an injury while bench-pressing $175 \mathrm{~kg}$. On physical examination, he had a diminished anterior axillary fold ("s" sign) deformity of the left pectoralis muscle with dimpling. The left nipple was sitting and pointing more downward than the contralateral nipple ("dropped nipple" sign) (Figure $1 \mathrm{~A})$. He reported weakness and pain with adduction and internal rotation of the shoulder but had normal muscle power and sensation. He was unable to perform his required military duties, which involved heavy lifting and a mandatory physical fitness test, or recreational weight lifting. Chest magnetic resonance imaging showed complete rupture of the sternal head of the pectoralis major muscle at the musculotendinous junction (Figure 1B). This distinctive chest deformity resulted from medial retraction of the ruptured sternal head.

Pectoralis major rupture is a highly debilitating injury, typically characterized at early presentation with a large subcutaneous hematoma and swelling. Because of the patient's military deployment and delayed presentation, he presented with chest deformity only, after the subcutaneous hematoma and swelling had resolved. He underwent surgical reconstruction using a tendon allograft. Four months postoperatively, his symptoms resolved and he returned to military activity.

Pectoralis major rupture is an uncommon sports injury that has become more prevalent in the past 20 years. ${ }^{1}$ The incidence of pectoralis major rupture among members of the military has been estimated at 60 per 100000 person-years. ${ }^{1}$ It affects men almost exclusively, and is typically a result of eccentric muscle contraction during sports activities - most commonly, bench-pressing, wrestling and American football. ${ }^{2}$ Although conservative management has traditionally been the first-line treatment, surgical repair is now recommended, particularly in young athletes. ${ }^{2}$

Surgical repair of chronic tears differs from acute tears, as the repairable length of the tendon may not be fully retrievable for fixation, so sutures are likely to cut through the retracted muscle tissue. Augmentation of the fixation with tendon allograft improves the mechanical strength of the repair and is associated with excellent outcome scores, minimal residual pain, satisfactory cosmetic results and good return of strength. ${ }^{3}$

\section{References}

1. Balazs GC, Brelin AM, Donohue MA, et al. Incidence rate and results of the surgical treatment of pectoralis major tendon ruptures in active-duty military personnel. Am J Sports Med 2016;44:1837-43.

2. Bodendorfer BM, Wang DX, McCormick BP, et al. Treatment of pectoralis major tendon tears: a systematic review and meta-analysis of repair timing and fixation methods. Am J Sports Med 2020 Feb. 28 [Epub ahead of print]. doi: 10.1177/0363546520904402.

3. Long M, Enders T, Trasolini R, et al. Pectoralis major tendon reconstruction using semitendinosus allograft following rupture at the musculotendinous junction. JSES Open Access 2019;3:328-32.

\section{Competing interests: None declared.}

This article has been peer reviewed.

The authors have obtained patient consent.

Affiliations: Tri-County Orthopedics (Parnes), Carthage Area Hospital, Carthage, NY; Tomaino Orthopedic Care (Tomaino), Rochester, NY

Content licence: This is an Open Access article distributed in accordance with the terms of the Creative Commons Attribution (CC BY-NC-ND 4.0) licence, which permits use, distribution and reproduction in any medium, provided that the original publication is properly cited, the use is noncommercial (i.e., research or educational use), and no modifications or adaptations are made. See: https://creativecommons.org/licenses/by-nc-nd/4.0/

Correspondence to: Nata Parnes, nparnes@cahny.org 